\title{
Providing Equivalent Learning Activities with Software-Based Remote Access Laboratories
}

\author{
http://dx.doi.org/10.3991/ijoe.v9iS3.2541 \\ Alexander A. Kist and Badri Basnet \\ University of Southern Queensland, Toowoomba, Australia
}

\begin{abstract}
Laboratory-based learning activities are important components of engineering and surveying education and it is difficult to offering practical activities to distance education students. Remote Access Laboratory (RAL) systems are widely discussed as learning tools to offer students remote access to rigs or hardware. In some disciplines laboratory activities are purely software based and RAL systems can be used to provide access to software. As part of a larger study into the transferability of the remote laboratory concept to non-engineering disciplines this project evaluates the effectiveness of RAL based software activities in supporting student learning is investigated. In the discipline of Surveying and Spatial Science, RAL technology is used to provide Geographic Information System software access to distance students. The key research question discussed in this paper is whether RALbased software activities can address the same learning outcomes as face-to-face practical classes for software activities. Data was collected from students' discussion forums, teaching staff diaries and teaching staff interviews. The project demonstrates that students undertaking learning activities remotely achieve similar learning outcomes than student in practice classes using the same software. Ease of system access and usability are critical and the learning activity needs to be supported by comprehensive learning materials. This research provides a clear case in which the use of RAL technology has provided inclusive educational opportunities more efficiently and these general results are also applicable to experiments that involve physical hardware.
\end{abstract}

Index Terms-Geographic Information Systems, Remote Access Laboratories, remote laboratories, software experiments, conceptual experimentation.

\section{INTRODUCTION}

Remote access laboratories have been widely discussed as alternative means to provide offside access to hardware-based experiments. This includes individual experiments [1, 2] as well as large infrastructure initiatives such as Labshare [3] or iLab [4] projects.

The University of Southern Queensland is regional university with a large external student cohort. In the Faculty of Engineering and Surveying $76 \%$ of the students are not located on campus and study via distance education. One key difficulty for distance education in engineering programs is how students are exposed to practical learning activities. Traditionally, on-campus residential schools form an important part of the engineering programs. These are also an important requirement for program accreditation by Engineers Australia (Similar to ABET [5] in the United States).
Because of this reason, it is currently not possible to replace complete on-campus practice classes with RAL learning activities. Accreditation of Surveying and Spatial Science programs on the other hand do not have the same stringent face-to-face attendance requirements. Therefore, this study focuses on a well-integrated RAL learning activity in Surveying and Spatial Science discipline that replaces a one week residential school for distance students using Geographic Information Systems (GIS) software.

In the same discipline, the RAL system is also being used as a mechanism to provide software access to distance students in other academic GIS courses. The aim of using RAL is to reinforce the understanding of the theoretical concepts and principles of geographic information systems through linked hands-on exercises. In the exercises, students are expected to apply theoretical concepts \& principles of GIS in analysing spatial data and creating map outputs.

Developing RAL learning activities in the context of distance education has its own challenges and requirements. In a faculty driven effort a RAL system was developed that integrates with the learning management system and enables mediated and authenticated access to both software and hardware experiments. Traditionally, software experiments have not been included in the definitions of what constitutes a remote access laboratory.

In an effort to make RAL available to other disciplines outside of engineering, Kist et al. [6] has shown how the concept of remote laboratories can be expanded. The authors propose that "laboratories and learning experiences should be understood separately. The former comprises a physical or conceptual space in which an event or experience takes place, the latter, the experience itself allows the application of knowledge to develop skills and understanding." This was motivated by the observation that learning and teaching perspective offers no compelling reason to specifically exclude software activities. A clear conclusion of previous evaluations [7] was that from a student perspective, computer-based RAL learning activities should not be treated differently to other online learning activities as student generally do not make that distinction.

Based on behavioural, cognitive and social learning theory, Barak [8] derives four principles to support computer-based learning activities, i.e. "learning is contextual, learning is an active process, learning is a social process and reflective practice plays a central role in learning” [pp. 122-123]. With regards to Barak's principles this study examines the effectiveness of RAL based software activities in support of student learning. This project investigates the research question whether RAL-based software 
activities can achieve the same learning outcomes as faceto-face practical classes. Data were collected from students' discussion forum, teaching staff diaries and via interviews with teaching staff members.

The remainder of the paper is organised as follows: Section 2 discusses the theoretical framework and the RAL system in more detail. The specific learning activity that has been the focus of this study is introduced in Section 3. Section 4 outlines the methodology that was used. Results are presented in Section 5 and findings are discussed in Section 6.

\section{BACKGROUND AND THEORETICAL FRAMEWORK}

\section{A. Enabling Learning Episodes with RAL}

RAL activities have been widely discussed as teaching tools to control hardware remotely in engineering disciplines. Early examples include robots [1] and control labs [2]. In an attempt to make RAL technology and related learning activities accessible to non-engineering disciplines, Kist et al. [6] have expanded the traditional concept of RAL to conceptual experimentation in any form which is conducted remotely.

RAL-based laboratory activities in engineering disciplines are conducted online remotely. White [9] suggests that laboratory experiments can create "episodes": "recollections of events in which the [learner] part or at least observed," with the result that the experience is "linked to propositions [about facts, concepts, ideas] so that those propositions in turn are remembered and understood” [pp. 765-766]. This suggests that laboratory experiments and the related learning experience can be examined separately.

These questions the traditional assumption, that a laboratory is only determined by the experiment - from an educational perspective the learning experience is more important. Physical or conceptual spaces make up the experiment where events take places and the application of knowledge to develop skills and understanding form part of these experiences or events. A remote laboratory may be defined as an event that creates a learning experience via a remote interface to connect the students' understanding of relevant information, concepts or ideas (propositions).

An "environment, in which the pupil can construct knowledge and can reflect upon his(/her) interactions and thinking" is also important [10] and enforces that "learning implies the initiation of a thinking process” [p. 228]. Slangen \& Sloep [10] citing Jonassen [11] identify three general thinking tasks and suggest that mind tools promote fluency in different ways of thinking. "Mind tools are computer applications that, when used by learners to represent what they know, necessarily engage them in critical thinking about the content they are studying ..." [12] and "they require students to think about what they know in different, meaningful ways" [p.24]. Consequently, RAL learning activities could be classified as a mind tools.

Barak's [8] instructional principles on the effective design and use of ICT supported learning, also apply to ICT based laboratory work and include: "learning is contextual, learning is an active process, learning is a social process, reflective practice plays a central role in learning” [8, pp. 122-123]. These principles are derived from behavioural, cognitive and social learning theory; are not discipline specific and also apply to RAL learning activities.

The ultimate measure of success for a RAL-based learning activity is whether it delivers the intended learning outcomes as "the pedagogical effectiveness of any educational activity is judged by whether or not the intended learning outcomes are achieved" [13].

\section{B. GIS and RAL}

GIS concepts and principles deal with the management and processing of spatial data from the real world. Often the aim is to make appropriate site-specific decisions for a particular purpose. In this context, learning theoretical GIS concepts and principles while using them practically via software based hands-on exercises to resolve real life problems is critical in student learning. However, offering parallel hands-on learning opportunities has not been feasible in the past due to very high (more than 90\%) enrolment of GIS students in a distance mode of study.

The arrival of RAL technology has offered a viable alternative to this limitation. GIS students are now able to access and use GIS software via RAL from the comfort of their homes while studying GIS in a distance mode. Therefore, RAL-based hands-on GIS exercises have been designed, developed and promoted among distance students in GIS courses.

In recent years there has been a significant improvement in; RAL technology, GIS software tool, and learning management system. The RAL system has become more user-friendly (e.g. provided access to network drives for data acquisition and savings). The GIS software used via RAL (e.g. ArcGIS) went through several version upgrades. The learning management platform became more user-friendly and provided better student learning experiences through custom-designed course homepages. Hence, the use of RAL technology in learning and teaching GIS courses has been the focus of this study.

\section{DESING OF THE LEARNING ACTIVITIES}

Opportunities to complete hands-on GIS exercises via RAL were offered in years 2010 to 2012 in two different GIS courses. In a practice-based GIS course (GIS2901 Geographic Information Systems Practice 1) completion of the given hands-on exercises and correct answering of the given task-related questions was a requirement. Students were required to successfully complete this assessment task to pass the course. The assessment questions were the same irrespective of whether students were attending this course in an on-campus (i.e. face-to-face) or a distance (via RAL) mode. The enrolment in this course varied between 8 and 10 students per year. Course objectives include to 'understand and interpret satellite images visually; perform basic image processing tasks to interpret and apply satellite imagery; build and manage spatial and attribute data in GIS; perform GIS data pre-processing and processing operations; and, design and produce map layout using GIS.

In the introduction to GIS (GIS1402 Geographic Information Systems) course, the use of RAL was voluntary. This course normally has an enrolment of up to 250 students with more than $90 \%$ studying in a distance mode. However, only 15 - 20 students/year have attempted RAL 
based exercises in years 2010 to 2012. Learning hands-on GIS skills was the main objective of the given exercises. There was no assessment associated with the task. Participating students were encouraged to contact tutor for clarification when required. In both courses, some students were able to access GIS software via alternate (nonRAL) methods.

The learning activities were designed to include three distinct steps; (a) access to RAL, (b) running GIS software on RAL computer, and (c) performing hands-on GIS exercises. Ease of access to RAL is the pre-requisite for any RAL based learning activity. Therefore, a clear set of step-by-step RAL start-up guide with screen-captured images, was developed, tested and distributed to students via relevant course homepage. Ease of logging in and out of the RAL computer was the primary focus of this guide. Participating students were required to complete this exercise before moving on to the next task.

ArcGIS has been the conventional GIS software used in teaching GIS courses at the university and hence access to this software was offered via RAL. A step-by-step guide to running ArcGIS on RAL computer was developed, tested and provided to students via course homepage. Successful running of ArcGIS software on RAL computer and seamless access of data from a network drive and saving output to a different network drive was the focus of this guide. Students were encouraged to complete this step before moving on to the next task.

After successful completion of the above two steps student were ready to start with hands-on GIS exercises via RAL system. Following five sets of hands-on GIS exercises were developed specifically for RAL based application; (a) Introduction to ArcGIS - 20 pages with 22 questions, (b) Introduction to GIS data structure 19 pages with 28 questions, (c) Map output design -6 pages with one question, (d) Managing and querying spatial and attribute data - 9 pages with 15 questions, and (e) Elementary vector and raster data analysis - 10 pages with 12 questions. One set of hands-on exercise per week was offered via course homepage. at a regular interval (i.e. weekly).

The hands-on GIS exercises were designed to reinforce students' understanding of the GIS concepts and principles. After completion of each exercise, students were required to answer several questions concerning application of GIS concepts and principles in solving real life problems. These questions were mostly short answer type and required only few words or numbers to answer them. In some cases, students were required to attach images created as an output of a GIS process. Students were required to submit their answers for assessment. Assistance was provided to students throughout the semester via on-line 'ask question forum'. The hands-on exercises were designed to scaffold students' knowledge as they progress with additional hands-on exercises. Most students completed all five exercises.

GIS Practice 1 students were able to complete all the required tasks and submit their outputs online as required. The tasks they completed and submitted included answers to questions, plotted graphs, and maps. An example of a GIS output as a map completed and submitted by a student using RAL system and GIS software is shown in Figure 1.

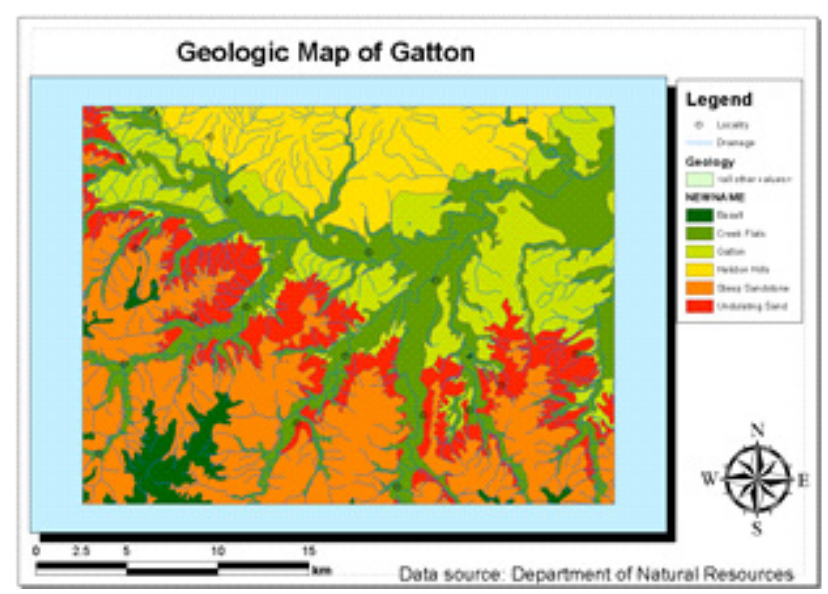

Figure 1. An example of map output design exercise.

\section{Methodology}

This project is part of a larger project that investigates the use of RAL technology in non-engineering disciplines [14]. Using five RAL project in different disciplines at various stages of implementation, the overall project has evaluated the success of the individual projects. A Program Logic Approach [15] was used to map inputs, activities, outputs and outcomes. Evaluation questions addressed the areas of appropriateness, efficiency, impact and sustainability. Through interviews with staff, student focus groups, observations of classes, a staff diary and analysis of student work comprehensive data were collected about the learning activities.

This paper reports on one specific software activity in the discipline of Surveying and Spatial Science. For this learning activity, data were collected from one staff diary, student online forums and student comments.

\section{RESULTS}

This study demonstrates that the RAL-based software activity addressed all four learning principles (i.e. learning is contextual, learning is an active process, learning is a social process and reflective practice plays a central role in learning) identified by Barak [11]. It has also demonstrated that distance students were able to achieve similar learning outcomes as on-campus (i.e. face-to-face attending) students through RAL based hands-on GIS software use. The results presented below were derived from both the GIS courses identified earlier.

\section{A. Learning is Contextual}

The RAL system offered a remarkable technological advantage in providing on-campus GIS software access to distance students at the comfort of their homes. The environment is very similar to the on-campus GIS laboratory. Students were able to complete the RAL based hands-on GIS exercises successfully and achieve the same learning outcomes as face-to-face students as indicated by the answers to the question they have provided. A sample answer of a student is shown in Figure 2.

Under normal circumstances, distance students would learn the theoretical concepts and principles of GIS in a distance mode and attend on-campus residential school at a later date to gain hands-on experience in real life application of GIS. 
Question 5. Use the Query Builder to find out the names of the two cities whose coordinates (latitude and longitude) are given below.

\begin{tabular}{|c|c|c|}
\hline City name & Latitude & Longitude \\
\hline Emerald $(\mathrm{QLD})$ & $23^{\circ} 31^{\prime} 23^{\prime \prime} \mathrm{S}$ & $148^{\circ} 9^{\prime} 29^{\prime \prime} \mathrm{E}$ \\
\hline Emerald (VIC) & $37^{\circ} 56^{\prime} 0^{\prime \prime} \mathrm{S}$ & $145^{\circ} 26^{\prime} 17^{\prime \prime} \mathrm{E}$ \\
\hline
\end{tabular}

Figure 2. Name of the cities correctly identified.

This discrete learning process has been a real disadvantage to distance learners as learning of theoretical concepts and principles was not happening in parallel with practical hands-on application of GIS. RAL technology has overcome this difficulty by providing learning opportunities to distance students at the time when it was required.

The contextual learning in this case was the use of oncampus GIS software via RAL at the time when they were learning theoretical concepts and principles of GIS in a distance mode. This would not have been possible for distance students in absence of RAL technology. Hence, RAL technology was the key to providing contextual learning environment to distance students. It is to be noted that contextual learning happens by default to on-campus students.

\section{B. Learning is an Active Process}

The objective of providing access to on-campus GIS software via RAL was to expose students to hands-on learning environments while learning theoretical concepts and principles of GIS. Hands-on learning is critical because people learn better through their own experiences. Therefore, having access to hands-on GIS exercises at the time of studying these GIS course was critical.

This opportunity was provided to students enrolled in GIS1402 course. A number of students were able to use the RAL system voluntarily to enhance their learning and they were clearly satisfied. Doing practical activities makes this an active learning exercise. Students were actively engaged with the learning activity as indicated by some of their comments.

Have just gone into RAL to complete GIS exercise and have noted the locality.shp data set has an error.

Active learning through hands-on exercises required constant interaction (to-and-fro flow of information) between the user and the software media. The RAL technology has made this interaction possible due to its provision for two-way interaction. Active learning through software use, in a distance mode, also required frequent interaction with the teaching staff. The teaching staff reported that providing timely support to students was critical to keep the active learning process alive, especially when RAL use was voluntary.

\section{Learning is Social}

While using GIS software via RAL, distance students were actively sharing their knowledge and experiences via dedicated discussion forums. When a student raised an issue (e.g. asked a question), fellow students attempted answering the question and/or sharing their own experiences. An example of a prompting question posed by a student in the discussion forum is quoted below.

"Just completed the raster file exercise and produced the three maps. Apart from a different set of colours in each output there appears to be no other noticeable differences. Given the changes made to the original file I would have expected changes to position and size. Am I missing something. Fellow students what are your thoughts."

This is an example of a student exploring to learn through social interaction. They used the discussion forum as an avenue to interact and reflect on learning. Learning through this social interaction would not have been triggered in absence of RAL technology providing access to on-campus GIS software. Thus, RAL technology clearly provided opportunities for shared thinking and knowledge construction among students during the process of studying the course.

\section{Learning through Reflective Practice}

During the study period, students went through several hands-on GIS learning exercises in the RAL-based learning environment. There was a degree of difficulty at the beginning in accessing on-campus GIS software via RAL. Then, there was some difficulty in using the GIS software itself. Hence, students' reflections were directed towards RAL based access system as well as GIS software-based exercises. The fact that RAL system together with handson GIS exercises has made students to reflect on their experience itself is valuable as reflective practices are crucial in student learning.

Literatures on reflection are united in suggesting that good reflection requires understanding the problem, observing the conditions, developing rational explanation and suggesting appropriate conclusion. In this study, the trigger of the entire reflective process was the RAL technology that provided access to GIS software to distance students. This reflective action can therefore be considered as a direct outcome of the RAL system.

\section{E. Learning Benefits}

The learning benefits of RAL system may be discussed under broader and specific learning headings. The broader learning benefits of RAL system may present itself in two folds. Firstly, the RAL system provided avenue for distance students to complete hands-on GIS exercises from the comfort of their homes. Secondly, it offered opportunities to complete hands-on GIS application based exercises remotely while studying GIS courses in a distance mode. Both of these have been significant benefits for distance students requiring to attend residential school oncampus under normal circumstances.

On the other hand, the importance RAL technology has been clearly demonstrated from its learning enhancement perspective as it has confirmed with all four Barak's learning principles.

\section{FINDINGS}

\section{A. Learning Outcomes}

Students are able to complete the same assignments externally that they previously did in class and the learning outcomes are addressed. There was no difference in the quality of work they produced, whether the work was completed by on-campus student in presence of the tutor or by distance students via RAL system.

Judging from the discussion forum post, it appeared that students using hands-on GIS exercises via RAL system were keen to discuss and reflect on their learning 
experiences. Usually face-to-face learners remain less active on the discussion forums. However, this requires further investigation.

The teaching staff of the course argue that the intensity of learning among RAL-based (i.e. external) GIS users was greater than that of the face-to-face users because external users were forced to think independently as they were working in an isolated environment. But, this argument requires further validation.

\section{B. Access and System Usability}

A primary driver for the RAL implementation that was examined in engineering was the issue of access for remote students. The GIS software being mastered is a large and expensive program previously available only to on-campus students using university computers. Making it accessible remotely allowed participation by students who would previously have had to come on campus for a residential school. Since many of these are international students, this represents a considerable cost to them. It also took up four days of the lecturer's time to run the residential school, with associated costs for the university. The focus of this evaluation was therefore whether there could be efficiencies in delivering the course remotely by using RAL techniques.

The Remote Access part of this RAL was initially problematic since students were logging on to proprietary software held on university servers. Intellectual property issues and the management of multiple access demands took some time to resolve but were eventually worked through.

Initially students had difficulties with the complexity of the system and the specific processes that were necessary to achieve the tasks.

"The RAL idea is great in theory, and I am grateful for its presence. However, each time I have to go through setting up the virtual computer, access the virtual computer, re-access the USQ website, copy then extract a zip file then bring up ArcCatalog. Maybe there's some kind of security requirements needed for this type of operation, but I think that the system could be improved. “

These issues were overcome by changes to the overall system as well as by providing comprehensive support materials and documentation for the students.

\section{Activity Design and Student Support}

Initially, RAL based hands-on GIS exercises were offered as one step process in which students were required to learn to access RAL, use GIS software on RAL and conduct hands-on GIS exercises simultaneously. This has caused a great deal of confusion and frustration among students. Some students went for alternative solutions (e.g. using software at workplace) to avoid RAL use.

This has led to the development of simplified instructions covering one step at a time. This included separate instructions for RAL access, running GIS software on RAL, and hands-on exercises. This measure was critical in providing a clear sense of achievement to students after completion of each step. This change has made students persistent in using RAL. About $50 \%$ of those interested using RAL, completed the RAL based GIS learning exercises. A handful of students requested for continuous RAL access even after the end of the course and the semester.
Prompt responses to student's inquiries via an ask question forum was critical to keep students motivated. This is especially true at the start of RAL use as some students would simply drop the idea if they did not receive help on time. At least 2 to 3 students per offer required lengthy telephone conversation to assist them at the initial stage of RAL access. However, once this hurdle was overcome, most students were happy to continue using RAL system.

\section{Staff Effort}

For the lecturer, a significant problem was to rewrite a course which had assumed face-to-face contact for the remote mode. This was a major task which involved both the building of the scenarios (the virtual lab space in this case) and the preparation of materials to be used to support learning and extra materials supporting use of the RAL. In order to build the virtual lab space "Data were to be acquired (searched), prepared in a desired manner and bring to appropriate size \& format. All the data were to be tested prior to posting. Errors were to be rectified as they become visible."

This work took 30 hours in total, including liaison with ICT support staff. In addition, writing learning support materials, exercises and questions and organising the online learning system took a further 18 hrs. In the period between 8 June 2011 and 30 August 2011, the lecturer spent 3 hours in responding to student queries. The busiest week of that period was 20 to 26 July when total student contact came to 54 minutes.

The 48 hours spent on building the RAL was a significant demand on the lecturer but it could be expected that subsequent semesters would see much smaller amounts of time spent in updating and correcting the materials developed this year. Even if taking the busiest week as the measure of how much time the lecturer spent in contact with students that would come to one hour per week or 13 hours for the whole semester (not counting marking). This compares favourably with the previous arrangement whereby the course was taught once face-to-face during semester plus offered as a residential school.

Students who use the RAL from remote locations were particularly appreciative of the well-structured course which made it possible for them to learn without the necessity of coming to a residential school. This is a clear case in which the use of RAL philosophy and technology has provided more inclusive educational opportunities more efficiently. It was probably helped by the fact that the task was basically an electronic one so that the use of computers for remote access had little impact once the system and the support materials had been created.

\section{CONCLUSIONS}

Remote Access Laboratories are excellent vehicles to provide external students with access to hardware as well as software experiments. This paper has demonstrated that software-based RAL experiments are viable learning activities. The four principles that have been identified by Barak for computer-based laboratory work are implemented. The scaffolded learning activities enable students to achieve learning outcomes that previously relied on face-to-face classes during residential school. The learning opportunities are effective as students no longer have to travel to attend residential school. 
This approach also offers an opportunity to include practical activities in academic courses such as; geographic data presentation, introduction to GIS, and spatial analysis and modelling courses.

Students are largely satisfied with the approach; however, frustration due to unsuccessful attempt to login to RAL can be serious problem. The design of three step process has been useful in providing a clear sense of achievement to student after completion of each step. The scaffolded learning activity can serve as an example for hardware activities. Most implications of this software only learning activity also apply to hardware RAL learning activities as well. Developing engaging activities requires a considerable effort by the academic to develop the learning activity and the associated learning materials. But it is expected that this leads to efficiencies in the future. In some instances, RAL learning activities can be a viable alternative to on-campus classes if sufficient additional study material and guidance is provided.

\section{ACKNOWLEDGEMENT}

The authors would like to thank Lesley Jolly and Hannah Jolly for their assistance with the evaluation and the Associate Deans (Learning and Teaching) at USQ for their support for this research project.

\section{REFERENCES}

[1] G. V. Kondraske, R. A. Volz, D. H. Johnson, D. Tesar, J. C. Trinkle, and C. R. Price, "Network-based infrastructure for distributed remote operations and robotics research," Robotics and Automation, IEEE Transactions on, vol. 9, pp. 702-704, 1993. http://dx.doi.org/10.1109/70.258062

[2] B. Aktan, C. A. Bohus, L. A. Crowl, and M. H. Shor, "Distance learning applied to control engineering laboratories," Education, IEEE Transactions on, vol. 39, pp. 320-326, 1996. http://dx.doi.org/10.1109/13.538754

[3] D. Lowe, S. Murray, L. Weber, M. De la Villefromoy, A. Johnston, E. Lindsay, W. Nageswara, and A. Nafalsk, "LabShare: Towards a National Approach to Laboratory Sharing," in 20th Annual Conference of the Australasian Association for Engineering Education (AaeE), University of Adelaide, 2009.

[4] V. J. Harward, J. A. del Alamo, S. R. Lerman, P. H. Bailey, J. Carpenter, K. DeLong, C. Felknor, J. Hardison, B. Harrison, I. Jabbour, P. D. Long, M. Tingting, L. Naamani, J. Northridge, M. Schulz, D. Talavera, C. Varadharajan, W. Shaomin, K. Yehia, R. Zbib, and D. Zych, "The iLab Shared Architecture: A Web Services Infrastructure to Build Communities of Internet Accessible Laboratories," Proceedings of the IEEE, vol. 96, pp. 931-950, 2008. http://dx.doi.org/10.1109/JPROC.2008.921607

[5] ABET. (2011, Criteria For Accrediting Engineering Programs. Engineering Accreditation Commission, ABET. Available: http://www.abet.org
[6] A. A. Kist, A. Maxwell, and P. Gibbings, "Expanding the Concept of Remote Access Laboratories " presented at the 119th ASEE Annual Conference and Exposition, San Antonio, Texas, 2012.

[7] A. A. Kist and L. Brodie, "Quality of Service, Quality of Experience and Online Learning," presented at the 2012 Frontiers in Education Conference, Seattle, Washington, 2012. http://dx.doi.org/10.1109/FIE.2012.6462223

[8] M. Barak, "Instructional principles for fostering learning with ICT: teachers' perspectives as learners and instructors," Education and Information Technologies, vol. 11, pp. 121-135, 2006. http://dx.doi.org/10.1007/s11134-006-7362-9

[9] R. T. White, "The link between the laboratory and learning," International Journal of Science Education, vol. 18, pp. 761 - 774, 1996. http://dx.doi.org/10.1080/0950069960180703

[10] L. A. M. P. Slangen and P. B. Sloep, "Mind tools contributing to an ICT-rich learning environment for technology education in primary schools," International Journal of Continuing Engineering Education and Life Long Learning, vol. 15, pp. 225239, 2005. http://dx.doi.org/10.1504/IJCEELL.2005.007712

[11] D. H. Jonassen, Computers as mindtools for schools: engaging critical thinking: Merrill, 2000.

[12] D. Jonassen, C. Carr, and H.-P. Yueh, "Computers as mindtools for engaging learners in critical thinking," TechTrends, vol. 43, pp. 24-32, 1998. http://dx.doi.org/10.1007/BF02818172

[13] F. Arango, C. Chang, S. Esche, K., and C. Chassapis, "A Scenario for Collaborative Learning in Virtual Engineering Laboratories," in 37th ASEE/ISEE Frontiers in Education Conference, Milwaukee, WI, 2007, pp. F3G-7 - F3G-12.

[14] A. A. Kist, P. Gibbings, and A. Maxwell, "From Individual Remote Access Laboratory Implementations to Institutional Learning Tools," presented at the IEEE EDUCON2013, Berlin, Germany, 2013.

[15] E. Taylor-Powell, L. Jones, and E. Henert. (2003). Enhancing Program Performance with Logic Models, University of Wisconsin-Extension, Feb. 2003. Available: http://www.uwex.edu/ ces/pdande/evaluation/evallogicmodel.html

\section{AUTHORS}

Alexander A. Kist is with the Faculty of Engineering and Surveying, University of Southern Queensland, Toowoomba, Australia (kist@ieee.org).

Badri Basnet is with the Faculty of Engineering and Surveying, University of Southern Queensland, Toowoomba, Australia (badri.basnet@usq.edu.au).

This work was supported in part by a USQ LTPF grant. It is an extended and modified version of a paper presented at the International Conference on Remote Engineering \& Virtual Instrumentation (REV2012), held at University of Deusto, Bilbao, Spain, July 4-6, 2012. Received 01 March 2013. Published as resubmitted by the authors 20 March 2013. 